\title{
Rectal Anastomotic Leakage
}

National Cancer Institute

\section{Source}

National Cancer Institute. Rectal Anastomotic Leakage. NCI Thesaurus. Code C78583.

Leakage due to breakdown of a rectal anastomosis. 